www.jmscr.igmpublication.org

Impact Factor (SJIF): 6.379

Index Copernicus Value: 79.54

ISSN (e)-2347-176x ISSN (p) 2455-0450

crossrefDOI: https://dx.doi.org/10.18535/jmscr/v6i10.147

IGM Publication

Journal Of Medical Science And Clinical Research

An official Publication of IGM Publication

\title{
To Study the Effectiveness of Para cervical Block in Accelerating Active Phase of Labour
}

\author{
Authors \\ Jayashree.$V^{1 *}$, Latha.$K^{2}$, Kavitha Devi .A ${ }^{3}$ \\ ${ }^{* 1}$ Associate Professor, Department of Obstetrics and Gynaecology, RMMCH, Annamalai University, \\ Annamalainagar - 608002 \\ ${ }^{2}$ Professor, Department of Obstetrics and Gynaecology, RMMCH, Annamalai University, \\ Annamalainagar - 608002 \\ ${ }^{3}$ Post Graduate, Department of Obstetrics and Gynaecology, RMMCH, Annamalai University, \\ Annamalainagar - 608002 \\ Corresponding Author \\ Dr Latha .K \\ Professor, Department of Obstetrics and Gynaecology, RMMCH, Annamalai University, \\ Annamalainagar - 608002, India \\ Email: shree_ram78@yahoo.co.in
}

\begin{abstract}
The objective of the study was to ascertain the effectiveness of paracervical block in acceleration of active stage of labour in antenatal mothers ${ }^{(1)}$ and to compare the results with controls, its effects on the fetus was also studied. Hundred cases of uncomplicated antenatal mothers with full term pregnancy were selected and randomized into two group of 50 each by single blind technique studied over a period of two years. The study was conducted using $20 \mathrm{ml} 1 \%$ Lignocaine in 50 study group \& and another $50 \%$ in control group didn't receive any medication. Time taken from administration of block to full dilatation was noted. It is noted from the study that paracervical block can accelerate the active phase of labour the $p$ value falls $(0.002)$ the cervical dilatation falls under $1.5 \mathrm{~cm}$ to $2 \mathrm{~cm}$ dilatation in the study group who have been given paracervical block for the patients ${ }^{(2)}$.

Keywords: Paracervical Block, Lignocaine, Apgar.
\end{abstract}

\section{Introduction}

Labour is considered to be the most happiest moment for both the mother and family but the time process consumed in the process makes the mother and the relatives anxious, thus the study in the past researches have been centred around shortening the labour period with pain relief effect. Paracervical block is considered to be the safest and the most effective and simple method which can be done without any anesthetist.

\section{Materials and Methods}

Antenatal cases in labour are randomly divided into study and control groups after explaining the procedure and getting consent. Study was conducted in Rajah Muthiah Medical College and Hospital.

Patient with following conditions are excluded from the study.

- Uteroplacental insufficiency 
- Diabetes, PET, post term, chronic Hypertension

- Malpresentation

- IUGR

- Multiple gestation

- Preterm

- PROM

- Congenital anomaly

- FHR aberrations

The study was conducted using $20 \mathrm{ml}$ of $1 \%$ lignocaine in 50 study cases and no medication in 50 control cases. Injection were given at 2,5,7 and 110clock position in the lateral vaginal fornix with paracervical block needle with guide. $5 \mathrm{ml}$ of lignocain was instilled at each position. Patients were monitored every 15 minutes for 30 minutes and then every $30 \mathrm{~min}$, partogram was maintained to assess the process of labour. Time taken from the administration of block to full dilatation was noted, Mode of delivery was noted. Neonatal condition was assessed by Apgar score at 1, 5 minutes.

\section{Result}

21 women (42\%) had 300 minutes in active first stage of labour, 11 women (22\%) had 240 minutes in active first stage of labour, maximum number of women in study group had active stage of labour below 5 hours. In control group 17 WOMEN (34\%) had 360 minutes in active phase of labour, 19 women (38\%) had 420 minutes in active phase of labour, maximum number of women in control group had active phase of labour above 5 hours.

The results are statistically insignificant $(\mathrm{p}<0.001)$

Duration of $1^{\text {st }}$ stage (Min) * Group

\begin{tabular}{|l|c|c|c|c|c|c|}
\hline \multirow{2}{*}{$\begin{array}{l}\text { Duration of 1st } \\
\text { Stage (Min) }\end{array}$} & \multicolumn{3}{|c|}{ Study } & \multicolumn{2}{c|}{ Control } & \multicolumn{2}{c|}{ Total } \\
\cline { 2 - 7 } & No. & $\%$ & No. & \% & No. & $\%$ \\
\hline 240 & 11 & 22.0 & 2 & 4.0 & 13 & 13.0 \\
\hline 260 & 1 & 2.0 & 0 & .0 & 1 & 1.0 \\
\hline 300 & 21 & 42.0 & 9 & 18.0 & 30 & 30.0 \\
\hline 320 & 0 & .0 & 1 & 2.0 & 1 & 1.0 \\
\hline 360 & 10 & 20.0 & 17 & 34.0 & 27 & 27.0 \\
\hline 400 & 1 & 2.0 & 0 & .0 & 1 & 1.0 \\
\hline 420 & 6 & 12.0 & 19 & 38.0 & 25 & 25.0 \\
\hline 470 & 0 & .0 & 1 & 2.0 & 1 & 1.0 \\
\hline 480 & 0 & .0 & 1 & 2.0 & 1 & 1.0 \\
\hline Total & 50 & 100.0 & 50 & 100.0 & 100 & 100.0 \\
\hline
\end{tabular}

\section{Chi-Square Tests}

\begin{tabular}{|l|l|l|l|}
\hline & Value & df & P value \\
\hline Pearson Chi-Square & 24.606 & 8 & 0.002 \\
\hline
\end{tabular}

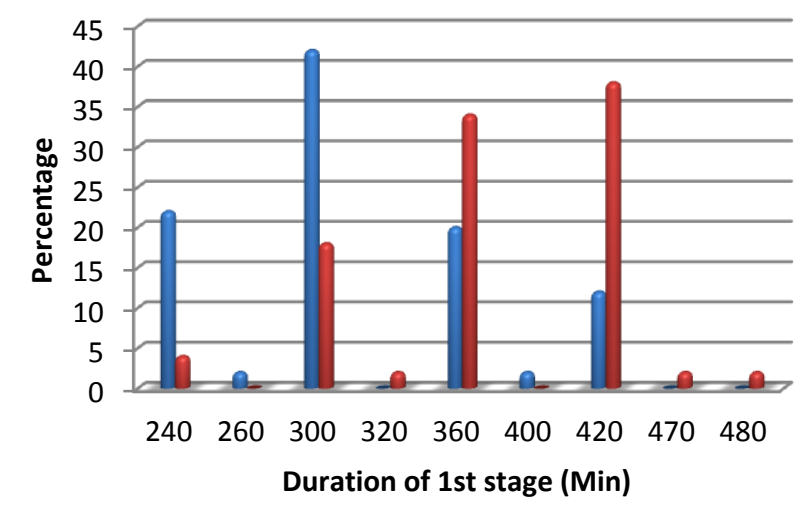

$\square$ Study

Control 


\section{JMSCR Vol||06||Issue||10||Page 881-885||October}

The rate of dilatation in study group for 23 women (46\%) have $2 \mathrm{~cm} / \mathrm{hr}$ dilatation and 14women $(28 \%)$ have $1.5 \mathrm{~cm} / \mathrm{hr}$ dilatation maximum number of antenatal mothers have dilatation above $1.5 \mathrm{~cm}$. In control group 20 women $(40 \%)$ have 1 $\mathrm{cm} / \mathrm{hr}$ dilatation, 23 women $(46 \%)$ have $1.5 \mathrm{~cm}$ dilatation $/ \mathrm{hr}$ maximum number of antenatal mother have dilatation below $1.5 \mathrm{~cm} / \mathrm{hr}$ dilatation. the $\mathrm{p}$ value is statistically insignificant $(\mathrm{p}<0.001)$ (5)

Rate of dilatation $(\mathrm{cm}) *$ Group

\begin{tabular}{|c|c|c|c|c|c|c|}
\hline \multirow{3}{*}{$\begin{array}{l}\text { Rate of dilatation } \\
(\mathrm{cm})\end{array}$} & \multicolumn{4}{|c|}{ Group } & \multirow{2}{*}{\multicolumn{2}{|c|}{ Total }} \\
\hline & \multicolumn{2}{|c|}{ Study } & \multicolumn{2}{|c|}{ Control } & & \\
\hline & No. & $\%$ & No. & $\%$ & No. & $\%$ \\
\hline 1 & 9 & 18.0 & 20 & 40.0 & 29 & 29.0 \\
\hline 1.2 & 1 & 2.0 & 0 & .0 & 1 & 1.0 \\
\hline 1.5 & 14 & 28.0 & 23 & 46.0 & 37 & 37.0 \\
\hline 2 & 23 & 46.0 & 6 & 12.0 & 29 & 29.0 \\
\hline 2.5 & 3 & 6.0 & 1 & 2.0 & 4 & 4.0 \\
\hline Total & 50 & 100.0 & 50 & 100.0 & 100 & 100.0 \\
\hline
\end{tabular}

\section{Chi-Square Tests}

\begin{tabular}{|l|c|c|c|}
\hline & Value & Df & P value \\
\hline Pearson Chi-Square & 18.327 & 4 & 0.001 \\
\hline
\end{tabular}

There was no significant difference in the duration of second stage and third stage in the study and control group

Duration of II $^{\text {nd }}$ stage (Min) * Group

\begin{tabular}{|l|c|c|c|c|c|c|}
\hline \multirow{2}{*}{ II $^{\text {nd }}$ stage (Min) } & \multicolumn{4}{|c|}{ Group } & \multicolumn{2}{c|}{ Total } \\
\cline { 2 - 7 } & \multicolumn{2}{|c|}{ Study } & \multicolumn{2}{c|}{ Control } & \multicolumn{2}{c|}{} \\
\cline { 2 - 7 } & No. & $\%$ & No. & $\%$ & No. & $\%$ \\
\hline 20 & 5 & 11.1 & 2 & 4.4 & 7 & 7.8 \\
\hline 30 & 33 & 73.3 & 27 & 60.0 & 60 & 66.7 \\
\hline 60 & 7 & 15.6 & 16 & 35.6 & 23 & 25.6 \\
\hline Total & 45 & 100.0 & 45 & 100.0 & 90 & 100.0 \\
\hline
\end{tabular}

\section{Chi-Square Tests}

\begin{tabular}{|l|c|c|c|}
\hline & Value & Df & P value \\
\hline Pearson Chi-Square & 5.407 & 2 & 0.067 \\
\hline
\end{tabular}

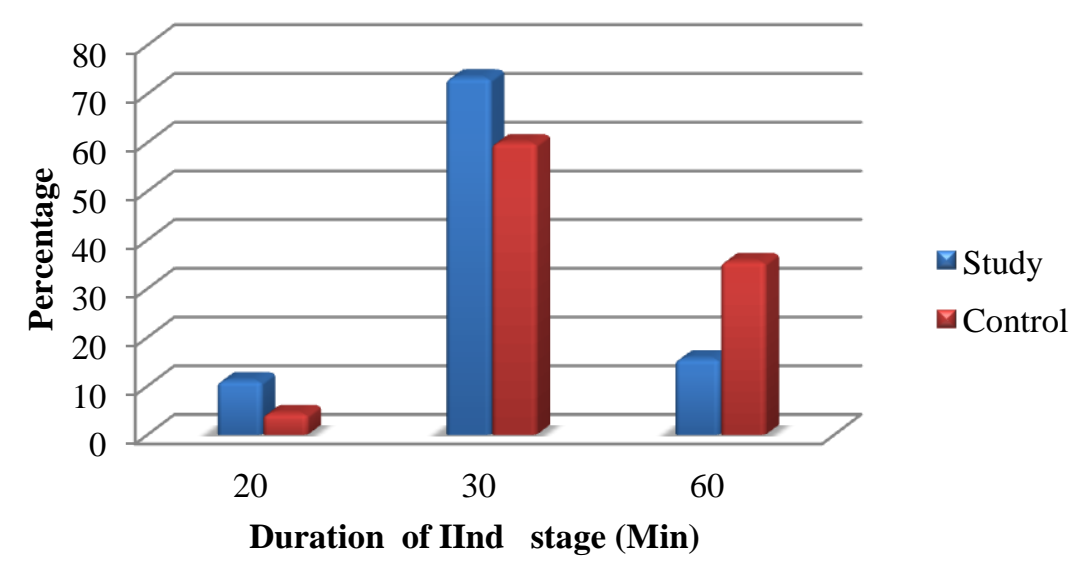


Duration of III $^{\text {rd }}$ stage (Min) * Group

\begin{tabular}{|l|c|c|c|c|c|c|}
\hline \multirow{2}{*}{$\begin{array}{l}\text { IIIrd } \\
(\text { Min })\end{array}$} & \multicolumn{5}{|c|}{ Group } & \multicolumn{2}{c|}{ Total } \\
\cline { 2 - 7 } & \multicolumn{2}{|c|}{ Study } & \multicolumn{2}{c|}{ Control } & \multicolumn{2}{c|}{} \\
\cline { 2 - 7 } & No. & $\%$ & No. & $\%$ & No. & $\%$ \\
\hline 5 & 24 & 53.3 & 21 & 46.7 & 45 & 50.0 \\
\hline 10 & 17 & 37.8 & 17 & 37.8 & 34 & 37.8 \\
\hline 15 & 2 & 4.4 & 3 & 6.7 & 5 & 5.6 \\
\hline 20 & 2 & 4.4 & 4 & 8.9 & 6 & 6.7 \\
\hline Total & 45 & 100.0 & 45 & 100.0 & 90 & 100.0 \\
\hline
\end{tabular}

Chi-Square Tests

\begin{tabular}{|l|c|c|c|}
\hline & Value & df & P value \\
\hline Pearson Chi-Square & 1.067 & 3 & 0.785 \\
\hline
\end{tabular}

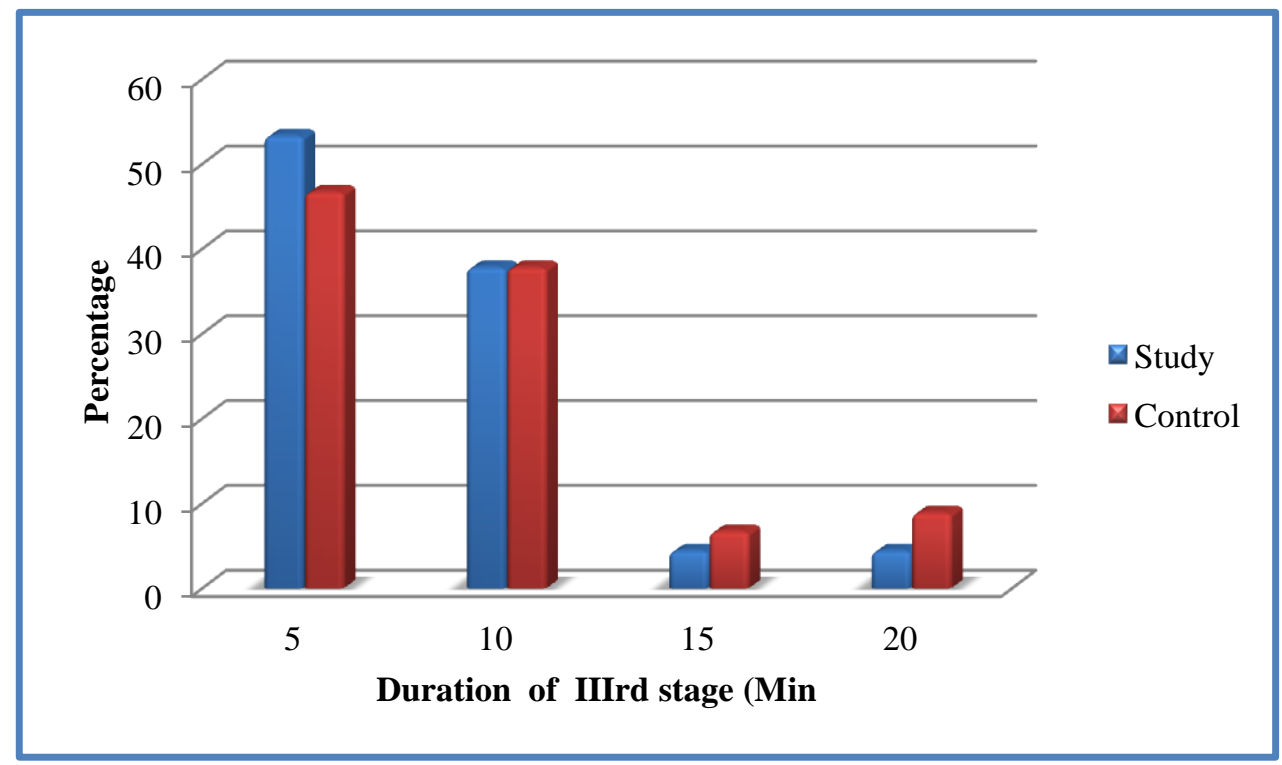

Apgar

\begin{tabular}{|l|c|c|}
\hline Apgar at 5 min & Study n (\%) & Control n (\%) \\
\hline$<4$ & 0 & 0 \\
\hline $5-7$ & $5(10)$ & $2(4)$ \\
\hline$>8$ & $45(90)$ & $48(96)$ \\
\hline Total & $50(100)$ & $50(100)$ \\
\hline$p=0.24$ & \multicolumn{2}{|c|}{ NS p > 0.05} \\
\hline
\end{tabular}

None of the babies in the study group asphyxiated

\section{Discussion}

The study conducted in rajah muthian medical college among control and study group using $1 \%$ lignocaine proved that paracervical block was helpful in accelerating the active phase of labour and reducing the period of labour.

Mean duration of labour was found to be reduced in study subjects when compared with standard duration of labour. Similar results were reported by Deshpande et al in their study ${ }^{(2)}$ The APGAR score is not affected by paracervical block as shown by the study of Nagal et $\mathrm{al}^{(4)}$, Latha $\mathrm{B}$. The results were found to be same in the randomized control study done by Z MEHRANGIZ ${ }^{(1)}$. 


\section{Conclusion}

PARA cervical block is the easiest and safest method which can be used without the expertise and helps in accelerating the active phase of labour which relives the mother from the excruciating pain sooner

\section{References}

1. Z Mehrangiz, R Sogra, A Malihe. Randomized Clinical Trial To Study The Effect Of Paracervical Block On Reducing Pain, Improving APGAR Score And On Accelerating The Active Phase Of Labor. The Internet Journal of Pain, Symptom Control and Palliative Care. 2003 Volume 3 Number 1.

2. Issue 2, Deshpande PS, Nitwe P, Walekar BR. Paracervical block in acceleration of active phase of labour in primigravidas. $\mathrm{J}$ Obstet Gynecol India 1989;39:314-6.

3. Maheswari NPM, Sethi SJ. Paracervical block in acceleration of active phase of labour in primigravidas. J Obstet Gynecol India 1995;42:506-9.

4. Latha.B, Nisha Kanchan. Randomized clinical trial to study the effect of paracervical block in accelerating the active phase of labour in primigravidas. Journal of International Academic Research For Multidisciplinary Volume 2,March 2014.

5. Friedman EA 1954 the graphic analysis of labour Am j obstet gynecot 68 1568-75. 